\title{
DESAFÍO AL ORDEN OLÍMPICO. AGUA, CAOS Y CORCELES \\ EN EL CARÁCTER Y PERSONALIDAD MÍTICA DE POSIDÓN
}

\author{
Julio López Saco \\ Universidad Central de Venezuela \\ julosa.ucv@gmail.com
}

\section{RESUMEN}

En el principal acto regulador para sostener el orden olímpico, el reparto del mundo con Zeus y Hades, a Posidón le corresponde el ámbito de las aguas. Su nombre, ciertos epítetos y varios episodios míticos apuntan facetas asociadas a la deidad, como los caballos, los toros y los terremotos. Este aspecto polifacético, clave para entender su personalidad y carácter, presenta además un arcaico y agreste poder vinculado con la fuerza del caos, que lo aleja de la comunidad cívica urbana. Por mediación de sus vehementes acciones, sus comportamientos vengativos y disuasorios, así como a través de las participaciones indirectas de buena parte de su monstruosa descendencia, Posidón intenta poner en jaque el orden olímpico instaurado por Zeus. Celoso de los dominios de su poderoso hermano, busca que se sientan los efectos de su violenta cólera desplegando sus singularidades más arcaicas, aquellas que le convirtieron en un funcional dios que agita y abraza la tierra, que provoca terremotos e inundaciones. En definitiva, se muestra como un dios que representa la virulencia de la naturaleza, la fuerza telúrica que amenaza el orden olímpico imperante.

PALABRAS CLAVE: caos, agua, caballos, mitología griega, Posidón.

\author{
CHALLENGE TO THE OLYMPIC ORDER. WATER, CHAOS AND STEEDS \\ IN THE CHARACTER AND MYTHICAL PERSONALITY OF POSEIDON
}

\section{ABSTRACT}

In the main regulatory act to sustain the Olympic order, the distribution of the world with Zeus and Hades, Poseidon corresponds the scope of the waters. His name, certain epithets and several mythical episodes point to facets associated with deity, such as horses, bulls and earthquakes. This multifaceted aspect, key to understanding his personality and character, also presents an archaic and aggressive power linked to the force of chaos, which alienates him from the urban civic community. Through his vehement actions, his vindictive and dissuasive behaviors, as well as through the indirect participation of much of his monstrous offspring, Poseidon tries to put in check the Olympic order set up by Zeus. Jealous of his powerful brother's domain, he seeks to feel the effects of his violent anger unfolding his most archaic singularities, those that turned him into a functional god who shakes and embraces the earth, which provokes earthquakes and floods. In short, it shows itself as a god representing the virulence of nature, the telluric force that threatens the prevailing Olympic order.

KeYwords: Chaos, water, horses, Greek mythology, Poseidon. 


\section{INTRODUCCIÓN}

Posidón es uno de los Olímpicos, hijo de Crono y Rea y, por consiguiente, hermano de Zeus.Fue criado por los Telquines y por una hija de Océano. Las tradicionesmás antiguas, que mencionan cómo Zeus, ya en su edad adulta, obliga a su padre Crono a devolver los hijos que había engullido, refieren que el padre de los dioses era el menor de la progenie. Sin embargo, con el paso del tiempo y el desarrollo de la primogenitura Zeus, en su papel de soberano, fue considerado el mayor de los hermanos, pasando a ser Posidón el menor. Ya en la Ilíada, Posidón tiene asignado el dominio sobre el mar, mientras que Hades reina en los Infiernos, y Zeus hace lo propio en el Cielo y la Tierra.

Este célebre reparto de lotes y competencias realizado entre Posidón y sus dos hermanos, Zeus y Hades, supuso una específica distribución de dominios del mundo, propia de una organización familiar divina, la de los dioses Olímpicos. Fue uno de los principales actos reguladores que sostendrían el orden olímpico. A Posidón le correspondió el mar. Sin embargo, el nombre de la deidad, algunos de sus epítetos y ciertos episodios míticos apuntan a la presencia de otras facetas íntimamente asociadas al dios, especialmente su carácter de deidad de los caballos y de los terremotos. Este aspecto polifacético será clave para entender su personalidad divina y su fuerte carácter, que hacen de Posidón una divinidad cargada de una fuerza y un poderío bastante envidiables. Sin embargo, es su especial relación con su poderoso hermano Zeus, especialmente a través de su agreste descendencia, como se entiende su singular carácter, su arcaica y fuerte personalidad, asociada con la fuerza del caos, un caos con el que, inútilmente, intenta poner en jaque el orden olímpico de Zeus.

En este sentido, se intentará hacer visible un más que probable rol del dios como peligro latente, pero a la vez fascinante y tal vez siempre acechante, así como evidenciar una funcionalidad que personifica un deseo de regreso al primitivismo inicial, caracterizado por el libre fluir de las aguas subterráneas, el poder telúrico y la fuerza indómita de toros y caballos, además de la ausencia de los esquemas coercitivos que impone la cultura, encarnados por el poderío civilizador de Zeus y de su numerosísima descendencia humana y semi humana.

\section{UN NOMBRE QUE HABLA: CARACTERÍSTICAS FUNCIONALES}

El análisis lingüístico del nombre Posidón (Carpenter, 2001: 42-43; Impelluso, 2003: 182-183; Grupo Tempe, 2003: 295-311 y ss.; y sobre su imagen LIMC, VIII, $1994, \mathrm{n}^{\circ} 28$, s.v. Poseidon) ${ }^{1}$ refiere un compuesto entre un término que significa señor,

\footnotetext{
${ }^{1}$ Véase sobre Posidón las referencias en Apol., Bibl., I, 2,2 y Hom., Il., XV, 186-188 y ss.
} 
que debemos contemplar en el sentido de amo de la casa o de dueño, y un segundo término que pareciera guardar relación con una denominación arcaica de la Tierra, visible en el nombre de Deméter (Tierra Madre), en un sentido de madre que nutre, alimentadora. En tal sentido, esta caracterización como Señor de la Tierra apunta a un aspecto propio de una deidad ctónica, telúrica. Compartiría entonces estas atribuciones con aquellas específicamente marinas. De hecho, algunos de los epítetos que se aplican al dios concuerdan con esta apreciación. Así, ennosígaios, aquel que conmueve la tierra, en tanto la sacude y la rodea, así como gaiéokhos, el que agarra con sus manos la tierra y, por tanto, la abraza, justifican con claridad su relación con lo telúrico (Bernabé, 2017: 267-269; Philippson, 1949: 104-115, capítulo "Poseidon, lo sposo della Terra") ${ }^{2}$. Platón hace ímprobos esfuerzos para aproximar la denominación Posidón con la capacidad del dios para contener el mar y sacudir la tierra, en tanto que en Tesalia se le conoce con el epíteto pétreo (Mylonopoulos, 1998: 86-87 y ss.; Bernabé, 2015: 191)³.

El nombre que refiere a Posidón está atestiguado en micénico, como po-seda-o-ne, denominación que se puede poner en relación con ciertos vocablos griegos, como es el caso de esposo (pósis), señora o soberana, esto es, pótnia, un epíteto cultual bien conocido que se aplica a determinadas diosas, y despótes, que se traduce como amo o dueño (Burkert, 1985: 136-137, n 1 y 138-140; y López Eire \& Velasco López, 2012: 346 y ss.; contribución en el mundo micénico Lévêque, 2006: 29 y ss.; y Chirassi Colombo, 2005: 17-18 y ss.) $)^{4}$. Es muy probable que la divinidad emergente en Pilos haya sido Posidón, debido a la evidencia de un santuario indicado con el nombre Posidaijo, así como la aparición de la denominación de una réplica femenina (Posidaijeia). Este hecho parece revelar una condición andrógina de la deidad, un elemento, además, que es bastante habitual en los panteones de la Edad del Bronce. Por tales motivos no debe sorprender que Homero ( $O d$., III, 24-26 y ss.) haya dicho que se trataba del dios más venerado del reino de Pilos (Chirassi Colombo, 1967: 947-952 y ss.; y Mylonopoulos, 1998: 87-88). Una afirmación nada baladí, sobre todo si se tiene en cuenta que su culto allí sería muy probablemente estatal.

${ }^{2}$ Sobre estos aspectos, Himno Homérico IV a Hermes, 186-187; Himno Homérico XXII a Posidón, 5-7; Diod. Síc., v, 52, 1-2, en donde se refiere la presencia de un hijo de Posidón denominado Ctonio; esto es, Subterráneo. Es posible que el epíteto gaiéokhos contenga una raíz cuyo significado sea el de conductor de carros en el mundo subterráneo, lo cual coincidiría con la atribución del dios a los terremotos y las fuentes bajo tierra. Un equivalente de ennosígaios es ennosídas, epíteto dórico, atestiguado ya en el micénico e-no-si-da-o-ne (Pínd., Pít. IV, 32, 174-175; Hes., Teog., 455), en el que el segundo término se relacionaría con Tierra Madre.

${ }^{3}$ Sim., PMG, 518, Frag., 149; Pínd., Pit. Iv, 137-139. En la antigüedad helena se aseguraba que los terremotos poseían un poder creativo. De aquí podría entenderse el apelativo Asphaleios aplicado a Posidón. En un orden semejante de cosas, en el ámbito hitita la fenomenología natural vehemente parece indicar una ruptura con la regularidad, estableciéndose así como una amenaza para el orden establecido.

${ }^{4}$ No está de más recordar aquí los adjetivos latinos potis y potens, poderoso, potente, como vocablos alusivos muy claros. 
Del mismo modo, su presencia en el ámbito micénico ha permitido plantear la hipótesis de que la deidad se haya configurado como una fusión entre una divinidad indoeuropea (denominativo Potis) y otra pregriega, el esposo de $D a$ (deidad madre, Mylonopoulos, 2005: 243-244 y ss.; Bremmer, 1990: 221), cuya presencia se habría consolidado en el seno del reino de Pilos.

Aunque Posidón no es una deidad de los ríos, divinizados en el mundo griego con sus particulares divinidades, dentro de sus atribuciones se encuentra la capacidad de hacer brotar las fuentes de agua, hecho que implica su función de dios de las aguas subterráneas. En este sentido, puede hacer brotar el agua con delicadeza, para calmar una larga sequía, o de un modo vehemente, provocando una inundación devastadora. Sea de una manera o de otra, utiliza una única herramienta, el tridente, con la que también conmueve, golpea, sacude y hace vibrar la tierra generando los terremotos.

El análisis lingüístico del nombre de la deidad así como de sus numerosos epítetos está de acuerdo con el hecho de que la palabra empleada para mar no es compartida por las lenguas indoeuropeas. Ello tiene que ver con que las poblaciones indoeuropeas procederían de territorios sin mar pero que en sus asentamientos encontrarían esa nueva realidad marina. Naturalmente, como nuevo dominio, debe suponerse que se asignaría a una especial y poderosa divinidad, en este caso, al señor del agua subterránea. Con el paso del tiempo, y con el desarrollo de la mitología marina, algunos de los mitos asociados a Posidón parecen encontrarse fuera de lugar, aunque su asimilación final será bastante completa.

\section{GENEALOGÍA: UN MUNDO CAÓTICO}

En su calidad de dueño y señor de los dominios marinos, el dios posee una consorte, Anfitrite, hija de Nereo, a partir de la cual entronca con antiguas divinidades acuáticas. Con ella engendra a Tritón, el ancestro de los seres marinos llamados tritones, que suelen acompañar formando parte de un gran cortejo de viejas deidades marinas, entre las que se encuentran Nereo, Glauco y Proteo, a la pareja Anfitrite-Posidón (iconografía, LIMC, I, 1981: Anphitrite, Reid, 1993: Poseidon, Anphitrite, Aghion \& Barbillon \& Lissarrague, 1997: Anfitrite y Neptuno; Grupo Tempe, 2003: 312-314 y ss.; deidades acuáticas, Bonnefoy, 1996: 112-114 y ss.; y Rudhardt, 1971: 54 y ss.) $)^{5}$. Aunque el dios también pretende a otra divinidad marina como Tetis, Posidón se establece con Anfritrite, en consecuencia, como señor de los mares por medio de su integración en una gran familia marina.

${ }^{5} \mathrm{Al}$ respecto, Avieno, Fenóm. de Arato, 699-791 y ss.; Baquíl., Epi., I, 7-8; Hes., Teog., 928-931 y ss.; Apol. Bibl., I, 4, 6; Paus. IX, 20, 5-7; Hom., Il., XIV, 200-202. La consorte de Posidón en las tablillas micénicas porta un nombre que deriva directamente del suyo, Po-si-da-e-ja. Al respecto de Posidón y Tetis, véase Apol. Bibl. III, 13, 6; Alceo V, 41; Pínd. Ist., VIII, 24-27 y ss. 
En compañía de una esposa como Anfitrite, el dios participa, no obstante, en una relevante serie de episodios míticos como dueño de la Tierra. Una unión entre Gea y Posidón, mar que ciñe y hace "temblar" a la tierra, da como resultado la figura de Anteo, enorme monstruo que habitaba en Libia ${ }^{6}$, y cuya fuerza debía a su madre. Además de Anteo, otros notables hijos de Posidón serán Orión, Busiris, los Lestrigones y Polifemo. Todos ellos, al menos en Odisea, parecen ajenos a la necesaria y humana cultura socio-política (Chirassi Colombo, 2005: 37-39 y ss.; y Lloyd, 2009: 56-79 y ss.; mitos en Odisea, Wathelet, 2002: 55-72)7. Se trataría, por lo tanto, de una descendencia próxima a las fuerzas del caos más arcaicas. Tal hecho pudiera hacer referencia al intento de Posidón de regresar al mundo caótico tras la imposición del orden por parte de Zeus, un ordenamiento que implicaba la instalación de una monarquía y una rígida jerarquía de rango y obediencia. Gran parte de la descendencia del señor de las aguas subterráneas estará formada por una estirpe de monstruosos hijos, violentos, maléficos, que acabarán siendo vencidos por diversos grandes héroes, como Heracles o Teseo.

Los enfrentamientos de los grandes héroes con los temibles hijos de Posidón pueden ser un eco de un antiguo conflicto por la soberanía. El gran Heracles vence y da muerte a Yalebión y Dercino, hijos del dios, porque intentaron robarle los ganados de Gerión en la región de Liguria, y se enfrenta también a otro de sus vástagos, al rey de Cos, Eurípilo, así como a Sileo. Se trata, claramente, de una descendencia completamente opuesta a la de Zeus.

Otros hijos suyos que siguen esta misma tipología serán Procrustes, Sinis y Cerción. El primero, por ejemplo se entretenía ajustando a los caminantes a su lecho, acortándolos o estirándolos lo necesario (rol limpiador de Heracles, Kirk, 2002: cap. 8, pp. 117-122 y ss. $)^{8}$. Esta serie de seres malignos que pueblan los territorios guardan relación directa con la vehemencia de quien es capaz de sacudir y conmover la Tierra, del monarca de los terremotos, aguas subterráneas y mares, que posee además, para llevar a cabo sus uniones, la capacidad de adoptar apariencias diferentes? Así, por ejemplo, Posidón se muestra como un carnero para engañar a Teófane, como delfín para relacionarse con Melanto, como ave para conocer a la terrible Medusa y como un caballo para poder acercarse a Deméter. Como novillo conquista a Eolia y con la forma de un río tiene la intención de acercarse a Tiro.

${ }^{6}$ Pínd. Nem. I, 63-66 y ss.; Íst., IV, 69 y ss.; Hig., Fab. 30; Apol. Bibl. II, 5, 12-13; Diod. Síc., IV, 17, 5; Luc. Fars., IV, 587-590 y ss.; Paus. IX, 11, 7.

${ }^{7}$ Hom., Od., I, 67 y ss.; IX, 105-107; X, 80-82 y ss.; XI, 100-103 y ss.. Véase también, Hig. Fab. 30 y 31, 56; Diod. Síc., IV, 18, 2; 26, 3; Aulo Gelio, Noch. Átic., XV, 20-22 y ss.; Apol. Bibl. I, 4, 6.

${ }^{8}$ Sobre Sinis, Cerción y Procrustes, Baq., Ditir., XVIII, 19-21 y ss.; Aulo Gelio, Noch. Átic., 15, 22; Hig. Fab., 38, 157 y 188.

${ }^{9} \mathrm{Al}$ respecto de la adopción de disímiles apariencias, Diod. Síc., IV, 67, 3; Apol. Bibl. I, 9, 7-9; Ovid., Met. VI, 114-116 y ss. 
El hecho de que Posidón sea capaz de adoptar distintas apariencias es un rasgo característico que concuerda con su control sobre los medios acuáticos. Además de poseer esa habilidad, puede concederla a otros, sobre todo por motivos amorosos. Es el caso de la transformación de Ceneo o la metamorfosis de su nieto, Periclímeno (asociación deidad, videncia y metamorfosis, Velasco López, 2000: 15 y ss.; 2007: 57-68 y ss.; López Eire \& Velasco López, 2012: 354-355) ${ }^{10}$, quien combate como sierpe, abeja o león contra sus contrincantes.

\section{EL DIOS CON LOS EQUINOS Y LAS FUENTES}

Rea también engaña a Crono cuando nace Posidón. Una leyenda arcadia señala que le habría burlado haciéndole ver a su marido que había dado a luz nada menos que un caballo. En consecuencia, le entrega un potro para que lo devore (Lloyd, 2009: 86-87 y ss.) ${ }^{11}$. Posidón mantendrá una peculiar relación con los caballos. En su encuentro amoroso con Deméter, la diosa, en su función de Tierra Madre, adquiere la forma de una yegua con la intención de escapar al abrazo intimidante del dios. En cualquier caso, logra unirse a ella en forma de equino y engendra a Despena, la Señora, además de un enorme y velocísimo caballo negro de nombre Arión. Otro notable ejemplo es la relación que mantiene con Hipótoe, "rápida como un caballo", o Melanipa, la "negra yegua". La unión con Deméter ${ }^{12}$ se lleva a cabo en un concreto lugar, junto a la fuente Telpusa, un hecho que aclara el vínculo existente entre los manantiales y los équidos.

Esta relación explica la frecuencia del epíteto Hipio asociado al dios, así como la presencia de santuarios, especialmente en Arcadia, dedicados a Posidón Hipio (Paus. VIII, 10, 3; 25, 8; caballo y ámbito cultual, Schachermeyr, 1950: 36-57 y ss.). En la iconografía (LIMC, VIII, 1994, n 151: Poseidon; Impelluso, 2003: 182; Carpenter, 2001: 40-42) se representa, bastante frecuentemente, a Posidón a lomos de un toro, un caballo o cabalgando seres híbridos, como es el conocido caso del hipalectrión, que combina un gallo y un equino, así como el muy célebre hipocampo, una mezcla de pez y caballo.

Tal vez el más conocido ejemplo equino en toda la mitología sea el de Pegaso, que nace de la cabeza de Medusa una vez que Teseo se la cercena, y que es el fruto habido de la relación entre ésta y Posidón ${ }^{13}$. Sin embargo, existen versiones que refieren de una manera muy directa la relación de Posidón con los caballos. En tal sentido,

${ }^{10}$ Apol. Rod., Argon., I, 155-157 y ss; Apol. Bibl. I, 9, 10; II, 7, 4; Hes. Frag. 33 b.

${ }^{11}$ Cf. Apol. Bibl. III, 6, 9; Ovid. Met., vI, 117-119 y ss.; Paus. VIII, 8, 1-3.

${ }^{12}$ Cf. Paus., VIII, 25, 4-5. En Hom., Il., XXIII, 345-348, se dice que Posidón se une a Erinis, término que debe ser entendido como un epíteto de Deméter.

${ }^{13}$ Sobre Pegaso, Apol. Bibl., II, 4, 2-3; Hig. Fab., 151, 2; Hes., Teog., 277-279 y ss. 
el primer caballo habría surgido en el momento en que el dios derrama su esperma sobre una piedra, en lo que sería una unión directa con la Madre Tierra. La gran variación femenina en el mito (Deméter, Medusa, la mismísima Gea), tal vez sea una metaforización de la monta como referencia a la culminación de la acción sexual ${ }^{14}$.

Una de las danaides, Amimone, a quien su padre había encargado ir en busca de agua, se encuentra con el dios y, a cambio de sus favores, devuelve el vital líquido a la árida tierra de Argos. Este episodio de las nupcias de Amimone con Posidón refleja la relación existente entre una mujer infecunda y la tierra yerma, muy reseca, e implica, del mismo modo, el estrecho vínculo entre los caballos y las fuentes (Lloyd, 2009: 91) ${ }^{15}$. Tal es de este modo que las denominaciones que reciben algunas Nereidas guardan relación directa con los equinos. Es el caso de Hipónoe, astuta como el caballo, Hipótoa, rápida como el caballo, y Menipa, aquella que tiene la fuerza de un caballo. Las fuentes, por otra parte, se configuran como los sitios alrededor de los cuales se organiza el culto en honor del dios Posidón en las regiones interiores de Grecia.

En el célebre episodio en el que Posidón compite con Atenea por el patrocinio de Atenas, el dios hace brotar fuentes golpeando con su tridente en la cima de la acrópolis ateniense (Grimal, 1989: 448 y ss.) ${ }^{16}$. En la Argólide, por su parte, provoca una devastadora inundación. En relación a su capacidad de transformación, este poder de hacer brotar las aguas se transmite a su descendencia equina. En tal sentido, por la acción de los cascos del caballo Pegaso surge la fuente Hipocrene en el monte Helicón. Se trata siempre de aguas que favorecen el canto y la inspiración poética (Velasco López, 2000: 125, inspiración por el agua) ${ }^{17}$. Esta relación se reforzaba, desde la perspectiva ceremonial y ritual, con la existencia de sacrificios

${ }^{14}$ Las hijas de Dánao, las Danaides se resisten a casarse con sus primos (los hijos de Egipto), porque, entre otros factores, no quieren ser tratadas como yeguas. Véase Esq. Supl., 429 y ss.; 140-144 y 286-290. Acerca de la cruda referencia al primer caballo, Esc. a Apol. Rod., Argon., III, 1245; Esc. a Licofrón, Alej., 764-766; Esc. a Pínd., Pit., IV, 245-247.

${ }^{15}$ Sobre Amimone y su encuentro con Posidón, Prop. Eleg., II, 25, 48 y ss.; Luc. Dia. Mar., 8; Eur., Fen., 186-188 y ss.; Hig. Fab. 169; Apol. Bibl., II, 1,5; Nonno, Dion., XLII, $405-408$ y ss.; Fil., Imag., I, 8,9. Además, sobre los nombres de resonancia equina de las Nereidas, Hes. Teog., 250; 261-262.

${ }^{16}$ En el momento en que los mortales se organizaron en ciudades, cada dios decidió escoger una o varias ciudades con la intención de ser venerados en ellas. En ciertas ocasiones, dos o tres divinidades elegían la misma población. Este hecho originaría conflictos, que debían ser sometidos al arbitraje de sus pares o de los propios mortales. En tales juicios, Posidón perdió habitualmente. No sólo en Atenas, sino también en Corinto, donde disputó con Helio, siendo el gigante Briareo el árbitro; en Egina, donde fue suplantado por Zeus; en Naxos lugar en donde fue vencido por Dioniso; o en Delfos, derrotado por Apolo. Su derrota ante Hera en Argos anticipará lo que aconteció en la Argólide. La región quedará sin agua por culpa de Posidón, pero el encuentro con Amimone propiciará la recuperación de las fuentes y manantiales.

${ }^{17}$ Acerca de la fuente ateniense y la inundación de Argólide, cf. Apol. Bibl., III, 14, 1-2; Ovid. Met., VI, 69-72 y ss.; Her., VIII, 54; e Hig. Fab. 164. Sobre la fuente Hipocrene, véase Estr. VIII, 6, 22; IX, 2, 26.27; Paus. IX, 31, 4; Hes. Teog., 5 y ss., Paus. II, 31, 8. 
de équidos en las fuentes del agua, tal y como se constata en diversas zonas litorales, como el conocido cabo Sunio, en donde hubo un templo que fue construido en época de Pericles en honor de Posidón (Aristóf., Los Caba., 560-562 y ss.; Burkert, 1985: 137-139 y ss.); un lugar en el que se le honraba organizando carreras de caballos.

Ahora bien, ¿cuál es la significación de esta apropiación? Posidón era una deidad que protegía a los navegantes y a los pescadores (cuyos arpones y anzuelos se asemejaban a su tridente), y que apreciaba los barcos, además de los caballos. Estos animales solían estar tradicionalmente asociados a las aristocracias (Olalla, 2001: 285-288; Schachermeyr, 1950: 64-68 y ss.; Burkert, 1985: 137-138 y ss. ${ }^{18}$, las cuales tenían tanto la capacidad económica de su mantenimiento como la necesidad de su empleo para vencer en las contiendas, sean éstas amorosas o militares.

\section{EL ÁMBITO RITUAL: MARES, CABALLOS Y TOROS}

Posidón le proporcionó a Pélope, en respuesta a un amor correspondido, un carro dorado cuyo tiro estaba conformado por caballos con alas. Con este carro, el héroe epónimo del Peloponeso fue capaz de ganar la carrera a Enómao, padre de Hipodamia. De este modo, y en virtud de un más que probable carácter iniciático de la prueba, una suerte de rito de paso hacia la madurez y la etapa adulta, conquistó la mano de Hipodamia. También Idas recibe del dios un carro tirado por alados caballos con el que raptará a Marpesa tras una competida carrera con otros pretendientes (mitos de Pélope, Préaux, 1962: 84; Lacroix, 1976: 329-334; Devereux, 1965: 8-17 y ss.; y Picklesimer Pardo, 1993: 12-16) ${ }^{19}$.

La relación de Posidón con la instauración de los grandes Juegos panhelénicos es patente. El santuario a él dedicado en el istmo de Corinto, punto estratégico de control de los mares, desempeña un destacado rol en el despliegue de los juegos Ístmicos. En estos juegos había ritualizadas carreras de carros. Otros destacados ritos asociados con el dios son el que como Posidón Hippios ${ }^{20}$ (escenarios rituales Detienne \& Vernant, 1988: 180-184 y ss.; Bernabé, 2017: 116-117 y n 70; Musti \& Torelli, 1991: 278-280 y ss.; y Lévêque, 2006: 171 y ss.) tenía lugar en el santuario beocio

${ }^{18} \mathrm{Al}$ respecto de la relevancia de los corceles para la aristocracia, Him. Hom. XXII a Posidón, 4-6.
${ }^{19}$ Baq. Ditir., XX; Enc. Frag. 20A, 19-20; Pínd. Olimp., I, 86-89 y ss.
${ }^{20}$ Himno Hom. IV a Hermes, 185-187; Paus. Ix, 26, 5; Hom., Il., II, 505-507. Onquesto recibe el nombre de un héroe epónimo que era, precisamente, hijo de Posidón. De esta localidad era natural Megareo (epónimo de Megara). Ambos se asociaban con Hipómenes, el que tiene un vigor análogo al de un caballo. Véase Ovid. Met., X, 604-607 y ss.; Hig. Fab., 185; Estr., VIII, 5, 1-3; Paus., III, 25, 3-4 y ss. Pausanias (III, 25, 8-9), informa que una fuente en Ténaro permitía observar, a los que miraban en sus aguas, los barcos y los puertos. En consecuencia, la función de la fuente se orientaba hacia la navegación, una clara competencia de Posidón. 
de Onquesto, o aquel llevado a cabo en el cabo Ténaro, un promontorio que se adentraba considerablemente en el mar.

Los cultos ofrecidos a Posidón son muy antiguos. Los más arcaicos remontan a la época micénica, en virtud de que el nombre del dios aparece atestiguado en las tablillas de Pilos, en el mítico reino del Néstor homérico, a quien Telémaco encuentra realizando un sacrificio a Posidón en el cual las víctimas propiciatorias son toros negros (vid supra) ${ }^{21}$. Del mismo modo que el caballo, el toro representa la vehemencia y masculinidad, aspectos que caracterizan a Posidón. Debe recordarse que fue un toro el que el dios hizo salir del mar tras las incesantes súplicas de Minos, el rey de Creta, quien le ofrecía un sacrificio. Minos promete a Posidón inmolarle el toro (López Eire \& Velasco López, 2012: 362-363 y ss.; y Díez Platas, 2005: 143-145 y ss.; probable dios-toro del II milenio, que Posidón heredaría, Lévêque, 2006: 90$)^{22}$.

De la misma manera, cuando el gran héroe Teseo le rogó a Posidón que castigase a su hijo Hipólito, cuyas yeguas habían perdido el control debido a un estruendo telúrico, fue un gran toro salvaje lo que le envió. El animal puso en fuga a las asustadas yeguas y provocó que el carruaje se volteara. Alcinoo, rey de los Feacios y descendiente del propio dios, quiso aplacar su furia ofreciéndole una docena de toros, mientras que Odiseo sacrificaría, entre otros animales, un toro a Posidón como desagravio por haber maltratado, cegándole, a Polifemo, vástago del dios ${ }^{23}$.

Los Eteobútadas eran los sacerdotes encargados del culto de Posidón Erecteo y, por tanto, los responsables de los sacrificios de toros que tenían lugar en Atenas en homenaje al dios. Tal función sacrificial se completaba con el arado ritual de los Búziges, que garantizaba la fecundidad de la tierra (Detienne, 1983: 127-129 y no 117; Price \& Kearns, 2004: Poseidon). En las Posideia, el sacerdote de Posidón, acompañado del de Atenea, se desplazaban hasta una localidad próxima a Atenas para realizar una arada ritual.

\section{VEHEMENCIA PRIMITIVA, VENGATIVA, CASTIGADORA Y DISUASORIA}

Algunos de los miembros del linaje que procede de Posidón y Amimone son protagonistas de acciones característicamente violentas y castigadoras. El fundador y héroe epónimo de Nauplia, Nauplio, hijo de Posidón, fue el padre de Palamedes,

${ }^{21}$ Hom. Od., III, 6-8 y ss. No es casualidad que se refiera la habilidad ecuestre de Néstor (Hom. Il., IV, 294-311).

${ }^{22}$ La posterior negativa de Minos, que se lo pensó mejor, propiciaría la concepción del Minotauro en el útero de su esposa Pasífae. Véase Apol. Bibl. III, 1, 3-4; 15, 8-10; Baq. Fragm., 26; Hig. Fab. 40.

${ }^{23}$ Eur., Hip., 886-888 y ss; 1202 y ss.; Hom. Od., XII, 130-132; XIII, 180-184 y ss. 
quien fue lapidado por los griegos a causa de las insidias de Odiseo. Palamedes había descubierto la estratagema de Odiseo para no acudir a la guerra de Troya. En venganza de los aqueos, Nauplio fue visitando los hogares de los diferentes héroes guerreros en Troya, propiciando desconfianzas, insidias y celos entre sus respectivas esposas. Además, fue el responsable de engañar a la flota griega que regresaba de Troya encendiendo una gran pira que confundió a los navegantes conduciéndolos hacia los arrecifes donde naufragarían.

La vertiente más violenta de Posidón tal vez pueda explicar, asimismo, el carácter de Cicno, el nieto de Pelias, el inadecuado comportamiento del propio Pelias hacia su hermano Esón, al que suplanta en el trono e, incluso, el que las hijas de Pelias se dejaran convencer son suma facilidad por Medea para descuartizar a su padre en su afán por rejuvenecerlo. Lo cierto es que Posidón aparece con diáfana claridad entre los antepasados de figuras míticas y héroes que heredan una suerte de violencia congénita y se hacen famosos por su mal comportamiento y su rebeldía hacia otras divinidades (Lloyd, 2009: 98-99 y ss.; y Kirk, 2002: cap. 6, pp. 102-113 y ss., conductas desafiantes $)^{24}$. Podría citarse el caso de Ticio, que intenta violentar, sin éxito a Leto, los desmanes de Orión, o el comportamiento de las Miníades, que se niegan a participar nada menos que en los rituales ofrecidos en honor de Dioniso.

Posidón encarna la brutalidad monstruosa e irracional, además de la violencia de los fenómenos naturales. El sacudidor de la Tierra no duda en castigar cuando entiende que es necesario. Así hace con los Gigantes, enfrentados a los dioses olímpicos. En cualquier caso, son necesarias las matizaciones. Posidón también puede premiar, como hace con los Centímanos por su decidido apoyo a los Olímpicos durante el desarrollo de la Titanomaquia (Hes. Teog., 711 y ss.; 815-818 y ss.; Suárez de la Torre, 2000: 639-643 y ss.). A pesar de que suele mostrarse inmisericorde cuando se irrita (con Odiseo, con Ayax), puede también mostrar su cara benévola y justa, llegando a acuerdos y pactos (véase infra). Posidón inflige castigos por mediación de grandes oleajes, terremotos y naufragios. Hace naufragar a Odiseo, abate a Hipólito e, incluso, propicia el seísmo que aterroriza a los espartanos en 464 a.e.c. ${ }^{25}$. Tal es así que la causa de su implacable castigo se atribuía tradicionalmente a la impiedad espartana contra el dios por haber expulsado unos suplicantes hilotas del templo consagrado en su honor en el cabo Ténaro.

${ }^{24}$ Hig. Fab., 95, 105, 116; Apol. Epit., III, 7-9; VI, 7-8; Eur., Hel., 765-767 y ss.; 1125-1130 y ss.; Quinto de Esm., Posth., XIV, 613-615 y ss.

${ }^{25}$ Hom. Od., v, 281-283 y ss.; Paus. II, 22, 4-5, quien menciona un santuario dedicado a Posidón Prosclistio (aquel que invade con olas) en el ágora de Argos; IV, 24, 5-7; Tuc., Hist. Guerra del Pelop., I, 127-130, 1; Her. VII, 128-131, 4-5; Esc. a Pínd., Pit., IV, 245-247. 


\section{FRUSTRANTE RELACIÓN \\ CON LAS CIUDADES Y LA CIVILIZACIÓN}

Se ha mencionado ya (supra, nota 16), la difícil relación que Posidón mantiene con las ciudades. Le resulta extremadamente complicado encontrar ciudades que deseen acogerse a su específico patrocinio y protección. Como ya se ha dicho, enfrentado a Atenea por la posesión del Ática, resultará vencido, muy probablemente porque sus dones, agua salada y caballos, no agradaban a los atenienses (Loraux, 1981: 117121 y ss.; Lévêque, 2006: 53-54 y ss. ${ }^{26}$. Naturalmente, Posidón no se tomará su derrota nada bien. Pudiera haber habido en ello, se podría argumentar, una implícita conexión entre los terroríficos poderes del dios y su ira incontenida en la derrota. El dios era considerado en Atenas una presencia incómoda en virtud de su estatus de dios peligroso. Resentido con el Ática, Posidón amenazará con inundaciones (en Argos hará lo contrario, propiciando la sequía). De modo específico se ensañará con las mujeres: las privará del voto; decretará que a ningún infante se le conozca por el nombre de su madre e, incluso, les prohibirá que sean llamadas ciudadanas. Además, uno de sus hijos, Halirroto ${ }^{27}$ (Bremmer, 1990: 199 y ss.; 211), atacará posteriormente los sacros olivos ofrecidos por Atenea en resentimiento por el veredicto que ha perjudicado a su padre.

Las dificultades que sus vástagos tienen para establecerse en las ciudades pueden ser un eco de las reiteradas derrotas que sufre el dios a la hora de convertirse en divinidad protectora de una comunidad cívica y político-social organizada.

Las disputas siempre tienen un idéntico resultado: el fracaso. Los fallidos intentos parecen relacionarse con el reparto de competencias y honores en el seno del panteón politeísta, así como con el desarrollo de la primera institucionalidad ciudadana (Sissa \& Detienne, 1994: 190-193 y ss.; y Otto, 2003: 19-22 y ss.; 41-43 y ss., sobre el gran poder del dios en toda la Hélade). El carácter de Posidón y sus específicos dominios parecen alejarle de un ámbito ordenado, justo y civilizado, que queda en manos de su hermano Zeus (Gallardo López, 1995: 273-274 y ss. Pactos y acuerdos de Posidón, Burkert, 1985: 189-190, y no 44) ${ }^{28}$. Las casi continuas derrotas

${ }^{26}$ Paus. I, 24, 5-6; Apol. Bibl. III, 15, 1; Paus. I, 26, 5-6; Ovid. Met., VI, 69-72 y ss.; Her., VIII, 54-56: Virg., Geór. I, 10-12 y ss. Existían pocas posibilidades de que la progenie del dios lograse superar el conflicto entre Posidón y Atenea.

${ }^{27}$ Arist., Nub., 1003-1006.

${ }^{28}$ Únicamente en Trecén, tras disputa también con Atenea, recibe Posidón (Plut., Vid. de Tes., 6, 1-2) el título de Polioukhos (poseedor de la ciudad), a la que patrocina. En algunos casos llega a ciertos acuerdos: con Helio, en Corinto (Posidón se queda con el Istmo y Helio con la parte alta); con Apolo, entregándole Delos y Delfos a cambio de Calauria, así como Pitó por Ténaro. Cf. Paus. II, 1-7; 30, 6-7; 33, 3. La relación de Posidón con Apolo no deja de ser especial. En el seno de la familia olímpica se convirtieron en tío (Posidón) y sobrino (Apolo), una familiaridad que recuerda la arcaica responsabilidad indoeuropea del tío en la educación del sobrino. Compartieron fatigas juntos, en concreto la servidumbre en Ilión a las órdenes de Laomedonte. 
en las disputas por la soberanía ciudadana con otras deidades debe inclinarnos a pensar, por lo tanto, que Posidón es una deidad ajena a las instituciones ciudadanas (López Eire, 2007: 98 y ss.). Como representante de la brutalidad y la violencia, no podía preverse otro destino para el dios.

Además, buena parte de su progenie (a diferencia de la de su hermano Zeus), tiene rasgos teriomorfos, utiliza lenguajes incomprensibles y posee comportamientos insociables, muy alejados de los valores que rigen la sociedad humana civiliza$\mathrm{da}$ (justicia, cultura, legalidad) y que son elementos esenciales, e irrenunciables, de la vida ciudadana de las comunidades político-sociales.

\section{CONCLUSIONES}

Las participaciones míticas de Posidón se corresponden cultualmente con el hecho de que las grutas y oquedades marinas, además de Ninfeos, le estaban consagradas, lo cual refleja el perfecto ensamblaje entre su carácter de señor de las aguas subterráneas y las fuentes y su calidad de deidad de los mares, bajo cuya protección de encontraba el litoral y los pescadores. Pero también sus mitos declaran el papel que el dios desempeña como ancestro tribal y promotor de rituales de iniciación de los jóvenes, que originan un poder unificador. Dicho rol le valdrá para convertirse en una deidad ampliamente venerada en las diferentes regiones de la Hélade, tanto en zonas interiores, en santuarios ligados a fuentes y manantiales, como en los territorios costeros.

Los enfrentamientos de Posidón o de sus hijos con Zeus aparecen en numerosos registros míticos. En tales encuentros Posidón parece intentar revertir el orden olímpico, que con tanto esfuerzo y dedicación su hermano desea implantar, tanto de una forma directa como por mediación de combates en los que se enfrenta su descendencia con el más renombrado vástago de Zeus, Heracles. Posidón se muestra celoso (Hom. Il., XV, 184-187 y ss.) de los dominios del padre de los dioses, y por ello busca que se sientan los efectos de su cólera y vehemencia a través de sus peculiaridades más arcaicas, en concreto aquellas que le convirtieron en un funcional dios que agita y abraza la tierra, que provoca seísmos e inundaciones. En el mencionado reparto del universo le correspondió el control de las aguas (subterráneas, marinas), asociadas con el ámbito caótico generador, un hecho que puede explicar que el dios sea susceptible de engendrar una monstruosa descendencia aunque también pueda, eventualmente, inaugurar linajes y suscribir pactos y alianzas.

El ideal de un mar variable, la concepción de un agua íntimamente ligada al caos primordial permitiría a ciertos autores antiguos, especialmente neoplatónicos (Proc., Comentarios a la Rep. de Platón, I, 113, 25-32; Brumble, 1998: 89, Neptune; Rudhardt, 1971: 87; Bonnefoy, 1996: 112-115 y ss.), interpretar de modo alegórico a un dios considerado capaz de contener en su seno la forma de todo lo engendrado, de mantener un equilibrio con el orden establecido, pero incapaz de imponer el desorden caótico ni con el control de sus ámbitos naturales ni por mediación de una descendencia que finalmente acabará sometida por los más prestigiosos héroes panhelénicos, no por casualidad hijos del ordenado y justo Zeus. 
Posidón, esa divinidad que encarna y representa la virulencia de los fenómenos de la naturaleza (incluida la platónica Atlántida), las primitivas fuerzas telúricas, y que manifiesta un comportamiento vengativo y poderosamente amenazante, devastador en ocasiones, con terremotos y diluvios, acaba siendo apaciguado, recluido y sometido al planificado ordenamiento de Zeus, una organización que representa la urbe, la sociedad ciudadana, la justicia y el control.

RECIBIDO: mayo 2019; ACEPTADO: junio 2019.

\section{REFERENCIAS BIBLIOGRÁFICAS}

Aghion, I. \& Barbillon, C. \& Lissarrague, F. (1997): Héros et dieux de l'antiquité: guide iconographique, Gallimard, París.

Bernabé, A. (2015): Mitos hititas. Entre oriente y occidente, Akal, Madrid.

Bernabé, A. (2017): Himnos homéricos. La "Batriacomiomaquia", Abada, Madrid.

Bonnefoy, Y. (1996): Diccionario de las mitologías y de las religiones de las sociedades tradicionales del mundo antiguo (Vol. II), Destino, Barcelona.

BREMMER, J. (1990): Interpretations of Greek Mythology, Routledge, Londres.

Brumble, H. D. (1998): Classical Myths and Legends in the Middle Ages and Renaissance: a Dictionary of Allegorical Meanings, Routledge, Londres.

Burkert, W. (1985): Greek Religion. Archaic and Classical, Oxford University Press, Oxford.

Carpenter, T. H. (2001): Arte y mito en la antigua Grecia, Destino, Barcelona.

Chirassi Colombo, I. (1967): «Poseidaion-Enesidaon nel Pantheon Miceneo», en Atti e memorie del I Congresso Internazionale di Micenologia, Roma, pp. 945-992.

Chirassi Colombo, I. (2005): La religión griega, Dioses, héroes, ritos y misterios, Alianza, Madrid.

Detienne, M. (1983): Los jardines de Adonis, La mitología de los aromas, Akal, Madrid.

Detienne, M. \& Vernant, J.-P. (1988): Las artimañas de la inteligencia. La "metis" en la Grecia antigua, Taurus, Madrid.

Devereux, G. (1965): «The Abduction of Hippodameia as "Aition" of a Greek Animal Husbandry Rite. A Structural Analysis», SMSR 36: 3-25.

Díez Platas, F. (2005): «El Minotauro: ¿Una imagen “al pie de la letra”»», Quintana 4: 141-152.

Gallardo López, M. D. (1995): Manual de mitología clásica, Clásicas, Madrid.

Grimal, P. (1989): Diccionario de la mitología griega y romana, Paidós, Barcelona.

Grupo Tempe [= M. Morillas, F. Morillo, M. R. Ruiz de Elvira, E. Crespo, E. Cuadrado, P. Jiménez, L. M. Macía, M. Martínez] (2003): Los dioses del Olimpo, Alianza, Madrid.

IMPELluso, L. (2003): Héroes y dioses de la antigüedad, Electa, Barcelona.

KIRK, G. S. (2002): La naturaleza de los mitos griegos, Paidós, Madrid.

Lacroix, L. (1976): «La légende de Pélops et son iconographie», BCH 100: 327-341.

LÉVÊQUE, P. (2006): Tras los pasos de los dioses griegos, Akal, Madrid.

LIMC = AA. VV. (1981-1987): Lexicon Iconographicum Mythologiae Classicae (10 vols.), Zürich - Munich. 
Lloyd, A. B. (ed.) (2009): What is a God?. Studies in the Nature of Greek Divinity, Classical Press of Wales, Swansea.

López Eire, A. (2007): «Rhetoric and Language», en I. Worthington (ed.), A Companion to Greek Rhetoric, Oxford University Press, Oxford.

López Eire, A. \& Velasco López M. (2012): La mitología griega: lenguaje de dioses y hombres, Arco Libros, Madrid.

LORAUX, N. (1981): «Le mythe dans la cité. La politique athénienne du mythe», en Y. BonnefoY, Dictionnaire des Mythologies, Flammarion, París, pp. 117-124.

MYlonopoulos, J. (1998): «Poseidon, der Erderschütterer. Religiöse Interpretationem von Erdund Seebeben", en E. Olshausen \& H. Sonnabend (eds.), Naturkatastrophen in der antiken Welt, Stuttgart, pp. 82-89.

MYlonopoulos, J. (2005): «Poseidon und Neptunus: Zwei Götter-Zwei polytheistische Systeme», Polifemo 5: 240-251.

Musti, D. \& Torelli, M. (1991): Pausania, Guida della Grecia (Vol. III. La Laconia), Milán.

Olalla, P. (2001): Atlas mitológico de Grecia, Road, Atenas.

Отто, W. F. (2003): Los dioses de Grecia, Siruela, Madrid.

Philippson, P. (1949): Origini e forme del mito greco, Einaudi Editore, Milán.

Picklesimer Pardo, M. L. (1981): La ascendencia indoeuropea de la figura de Herakles (estudio de mitología comparada) [Tesis Doctoral], Universidad de Granada.

PréAuX, C. (1962): «La légende de Pélops et la royauté sacrée», en L. DE Heusch, Le Pouvoir et le Sacré. Annales du centre d'études des religions, vol. 1, Bruselas, pp. 83-86.

Price, S. \& KeARns, E. (2004): The Oxford Dictionary of Classical Myth \& Religion, Oxford University Press, Oxford.

ReID, J. D. (1993): The Oxford Guide to Classical Mythology in the Arts 1300-1900s (2 vols.), Oxford University Press, Nueva York.

RUDHARDT, J. (1971): Le thème de l'eau primordiale dans la mythologie grecque, Berna.

SCHACHermeYR, F. (1950): Poseidon und die Entstehung des griechisches Götterglaubens, Berna.

Sissa, G. \& Detienne, M. (1994): La vida cotidiana de los dioses griegos, Temas de Hoy, Madrid.

SuÁrez de la Torre, A. (2000): «Archilocus' “Biography”. Dionysos, and Mythical Patterns», en

M. Cannatà Fera y S. Grandolini (eds.), Poesia e religione in Grecia. Studi in onore di G. Aurelio Privitera, Nápoles, pp. 639-658.

Velasco López, M. H. (2000): «Metamorfosis y videncia en las tradiciones griega e irlandesa», Minerva 14: 11-47.

WATHelet, P. (2002): "Leçons à tirer des mythes de l'Odyssée", en J. A. López FérEZ, Mitos en la literatura griega arcaica y clásica, Ediciones Clásicas, Madrid, pp. 55-72. 